\title{
APRENDIZAJE DOCENTE Y NUEVAS PRÁCTICAS de lenguaje. Posibilidades de formación EN EL GIRO DIGITAL: RESEÑA
}

\author{
Mónica Elvira Rodríguez López \\ Estudiante Licenciatura en \\ Educación Básica con Énfasis \\ en Humanidades y Lengua \\ Castellana, Pontificia Universidad \\ Javeriana, Bogotá, Colombia. \\ E-mail: mo.rodriguez@javeriana. \\ edu.co
}

Título de la obra: Aprendizaje docente y nuevas prácticas de lenguaje. Posibilidades de formación en el giro digital

Editoras: Judith Kalman y Michele Knobel

Traductora: María de Carmen Arriola Salazar

Editorial: Ediciones SM

País: México

Año de publicación: 2017

Número de páginas: 299

ISBN: 9786072424043
Michele Knobel y Judith Kalman, docentes e investigadoras de las nuevas prácticas del lenguaje, la alfabetización, la lectura y la escritura en entornos escolares y cotidianos, presentan en este libro una serie de ejemplos ilustrativos de lo que puede ser el desarrollo profesional docente desde el punto de vista de la práctica profesional y lo que significa ser un maestro que vive y trabaja durante las décadas tempranas de la era digital. Eso explica el énfasis en comprender las prácticas de lectoescritura y explorar las posibilidades de usar las tecnologías digitales de manera productiva y efectiva en contextos de aprendizaje formal.

El volumen está integrado por diez capítulos, los cuales articulan una serie de premisas en torno al desarrollo profesional, la introducción de las tecnologías de la información y la comunicación a través de programas gubernamentales que suministran equipos a escuelas en varios países del mundo, como México, Estados Unidos, Canadá, Australia, Finlandia, Noruega y Argentina.

Así, los capítulos permiten observar el papel de los maestros como modelos vivos concretos para cambiar y transformar sus actuales interpretaciones del currículo mediante nuevas perspectivas de aprendizaje, forjado en ambientes reflexivos y colaborativos. El propósito fundamental de estos materiales se soporta en dar a conocer la forma del desarrollo profesional que hace uso sensible y significativo de las nuevas prácticas del lenguaje y de las tecnologías digitales desde compromisos profundos entre significados, relaciones, conocimientos y pensamiento crítico.

En el prólogo, Colin Lankshear expone la complejidad de traducir el concepto literacy, ya que los autores de este libro manifiestan la dificultad de relacionar el concepto originalmente en inglés y que en castellano alude a alfabetización. Lankshear opta por definir este término con base en su significación; para ello discute prácticas de lenguaje multimodal e incluye comportamientos culturales. Para terminar, se describe cómo las políticas educativas y nacionales les exigen a los maestros una inversión de tiempo y recursos en reformas,

Recibido: 2019-02-18 / Aceptado: 2019-05-17 / Publicado: 2019-05-20

doi: 10.17533/udea.ikala.v24n02a13 
planes de estudio y esfuerzos encaminados a reorganizar las escuelas. Sin embargo, los docentes no desempeñan un papel central en dichas problemáticas; solo se tiene en cuenta su quehacer para evaluar y analizar resultados, los cuales muchas veces con calificados de decepcionantes.

Esto conlleva a concebir el desarrollo profesional, el cual es pregonado por muchas empresas comerciales que ofrecen servicios y productos para el fortalecimiento de las capacidades e iniciativas de enseñanza en los maestros, ligadas con las tecnologías digitales.

A lo largo de diez capítulos, el lector puede ir observando programas, proyectos y procesos que comprenden la inserción tecnológica, desde miradas más abiertas y conscientes, mediada por maestros que se apropian de la tecnología para forjar un ambiente de aprendizaje más enriquecedor y conveniente en las escuelas. Mediante el empleo de diferentes herramientas digitales se logra promover formas de participación colaborativa, reflexiva y crítica en ambientes digitales.

Esto se ilustra en el primer capítulo, donde se muestra un panorama liderado por una serie de programas nacionales en México que intenta impulsar el uso de la tecnología digital en escuelas primarias públicas. En ello se basa Lets al articular el entendimiento y las acciones para ayudar a los docentes a transformar sus prácticas y asimismo, aprender a articular la tecnología digital en sus clases. Los capítulos siguientes describen y analizan casos particulares de maestros que realizan actividades enfocadas en sus áreas de estudio, aprendiendo y desarrollando propuestas vinculadas con el uso de herramientas tecnológicas para forjar un aprendizaje más dinámico y abierto hacia los estudiantes en lugares como Estados Unidos, Canadá, Argentina, Australia, Noruega y Finlandia.

Estas experiencias determinan espacios en donde la educación no se limita a un papel tradicional del alumno, sino por el contrario, se concibe desde una perspectiva inclusiva e integradora de estilos, conocimientos entre estudiantes y sus familiares, y se comprende las distintas formas lectoescriturales que contribuyen en una comunidad de aprendizaje; ya que se brinda la posibilidad de generar una enseñanza enmarcada desde los intereses propios de los alumnos, fortaleciendo los lazos de compañerismo y comunicación.

Este libro permite explorar, contemplar y acceder a un panorama discursivo en torno al desarrollo profesional, vinculado estrechamente con las tecnologías digitales, el aula, los estudiantes y sus experiencias. Cada capítulo proporciona una mirada cercana y precisa sobre los procesos, proyectos y experiencias que se tejan alrededor de las TIC y los maestros, en función de una enseñanza aprendizaje liderada por discursos sobre la eficacia, laconectividad y la interacción con el otro. De esta forma, el aporte y la apuesta social que el libro plantea, se resaltan a través del uso de las tecnologías digitales como herramientas que fortalecen los constructos sociales y que no radican en un esquema establecido de aprendizaje. Por el contrario, impulsan una diversificación de maneras para poner en marcha procesos de aprendizaje y enseñanza enriquecedores y dinámicos que posicionan el aprendizaje social en un escenario vital.

Así pues, se visibilizan las tecnologías como reconstructoras de las relaciones entre profesores y alumnos, modificando las maneras como se asume y distribuye el aprendizaje. Por este motivo, los autores del libro ofrecen de forma colectiva diferentes ejemplos que describen la idea del aprendizaje determinado con los sujetos y sus habilidades.

Asimismo, se comprende que todo lo que trae consigo el aprendizaje conectado es una nueva perspectiva de ver el ejercicio profesional docente, porque abre el esquema a nuevas perspectivas de la contemporaneidad con las tecnologías actuales. Por ello, pensarse también más allá de la enseñanza necesita de un enfoque en el que el aprendizaje trascienda más allá de un ámbito académico y se conecte con aprendizajes que se vinculen a nuevos campos sociales.

Lo anterior aporta también a una perspectiva que resalta desde la segunda mitad del siglo XX una 
transformación que apunta a diversos procesos y acontecimientos en los que el leer y escribir también se transforman en espacios digitales. Así pues, al término literacy, legítimamente se la ha ido agregando una nueva dimensión.

El aporte del libro para educadores, administradores y formuladores de políticas educativas es comprender las formas de mitigación de la brecha entre tecnología, maestros y procesos de aprendizaje, las cuales no se soportan en reemplazos o esquematizaciones complejas y adaptaciones curriculares, sino que, por el contrario, son una incorporación y adentramiento a prácticas sociales necesarias y vitales para manejar nuevas dinámicas de conocimiento, enseñanza y aprendizaje en el aula.

How to reference this article: Rodríguez-López, M. E. (2019). Aprendizaje docente y nuevas prácticas de lenguaje. Posibilidades de formación en el giro digital: Reseña. Íkala, Revista de Lenguajey Cultura, 24(2), 441-443. DoI: 10.17533/udea.ikala.v24n02a13 